\title{
References
}

1 Koskela HO, Hyvärinen L, Brannan JD, et al. Responsiveness to three bronchial provocation tests in patients with asthma. Chest 2003; 124: 2171-2177.

2 Brannan JD, Anderson SD, Perry CP, et al. The safety and efficacy of inhaled dry powder mannitol as a bronchial provocation test for airway hyperresponsiveness: a phase 3 comparison study with hypertonic (4.5\%) saline. Respir Res 2005; 6: 144.

3 Kersten ET, Driessen JM, van der Berg JD, et al. Mannitol and exercise challenge tests in asthmatic children. Pediatr Pulmonol 2009; 44: 655-661.

4 Alblooshi AS, Simpson SJ, Stick SM, et al. The safety and feasibility of the inhaled mannitol challenge test in young children. Eur Respir J 2013; 42: 1420-1423.

5 Wood LG, Powell H, Gibson PG. Mannitol challenge for assessment of airway responsiveness, airway inflammation and inflammatory phenotype in asthma. Clin Exp Allergy 2010; 40: 232-241.

6 Anderson SD, Brannan JD. Bronchial provocation testing and collection of sputum with inhaled mannitol. Clin Exp Allergy 2010; 40: 193-196.

7 Zar HJ, Tannenbaum E, Hanslo D, et al. Sputum induction as a diagnostic tool for community-acquired pneumonia in infants and young children from a high HIV prevalence area. Pediatr Pulmonol 2003; 36: 58-62.

8 Fleming L, Wilson $\mathrm{N}$, Regamey $\mathrm{N}$, et al. Use of sputum eosinophil counts to guide management in children with severe asthma. Thorax 2012; 67: 193-198.

9 Fleming L, Tsartsali L, Wilson N, et al. Sputum inflammatory phenotypes are not stable in children with asthma. Thorax 2012; 67: 675-681.

10 Vizmanos-Lamotte G, Moreno-Galdó A, Muñoz X, et al. Induced sputum cell count and cytokine profile in atopic and non-atopic children with asthma. Pediatr Pulmonol 2013; 48: 1062-1069.

11 Pizzichini E, Pizzichini M, Efthimiadis A, et al. Indices of airway inflammation in induced sputum: reproducibility and validity of cell and fluid-phase measurements. Am J Respir Crit Care Med 1996; 154: 308-317.

12 Gibson PG, Grootendor DC, Henry RL, et al. Sputum induction in children. Eur Respir J 2002; 20: Suppl. 37, $44 s-46 s$.

\section{Successful treatment of antineutrophil cytoplasmic antibody-associated bronchiectasis with immunosuppressive therapy}

To the Editor:

The underlying mechanisms of bronchiectasis are poorly understood and the cause remains unknown in half of the patients [1]. Whether bronchiectasis is the direct consequence of pathogen aggression or of an abnormal immune response remains unresolved [2-4]. We report here the first case of a patient with bronchiectasis improved by an immunosuppressive regimen.

In 2010, a 27-year-old male nonsmoker was referred by his oncologist to our respiratory department (Hôpital Foch, Suresnes, France) for recurrent haemoptysis associated with anaemia at $90 \mathrm{~g} \cdot \mathrm{L}^{-1}$ and abnormal chest computed tomography (CT) scan.

He first sought medical advice in our hospital in 2008 for a testicular stage I nonseminomatous germ cell tumour. Despite the PT2 stage of the tumour (with vascular emboli) and the pure carcinoma histology, he declined to receive adjuvant chemotherapy and chose an active surveillance policy. This implied repeated CT scans and follow-up visits. The cancer was in complete remission in 2010.

He reported several episodes of cough and spitting, all considered as minor infections, even before the orchiectomy, but pulmonary symptoms continued to worsen. He had no other symptoms, was in very good shape otherwise, with a performance status of 0 , a weight of $80 \mathrm{~kg}$ and height of $180 \mathrm{~cm}$.

While the 2008 chest CT scan only exhibited bi-basilar micronodules, the chest CT scan performed in 2010 revealed bi-apical ground-glass opacities with a crazy paving pattern with interlobular septal 
thickening (fig. 1a) and bilateral cylindrical bronchiectasis with thickening of the bronchial wall, which appeared on lung bases (fig. 1a). The bronchoalveolar lavage (BAL), obtained during a fibreoptic bronchoscopy, exhibited a bloody fluid. Analysis showed a cellular count of 500000 cells.mL $\mathrm{mL}^{-1}$, with $14 \%$ neutrophils and $84 \%$ macrophages. The Golde score was calculated at 176 , confirming the diagnosis of diffuse alveolar haemorrhage (DAH). Microbiological tests remained negative. Perinuclear antineutrophil cytoplasmic antibodies (ANCA) were identified at a titre of 1/640 UI by immunofluorescence, with specificity against both myeloperoxidase (MPO) and bactericidal/permeability-increasing protein (BPI) on ELISA tests (ORGENTEC Diagnostika GmbH, Mainz, Germany). No extrathoracic manifestation was identified; hence, a diagnosis of a probable lung-limited microscopic polyangiitis was retained. No additional cause of bronchiectasis was detected: sinus CT scan, serum IgG, IgA, IgM, IgG subclasses, IgE, $\alpha_{1}$-antitrypsin, anti-cyclic citrullinated peptide antibodies, rheumatoid factor, Aspergillus precipitins, and antibodies against HIV or hepatitis $\mathrm{C}$ virus were undetectable or within normal values.

Prednisone (started at $1 \mathrm{mg} \cdot \mathrm{kg}^{-1} \cdot \mathrm{day}^{-1}$, then progressively withdrawn) and rituximab ( $375 \mathrm{mg} \cdot \mathrm{m}^{-2}$ weekly for 4 weeks) were started in October 2010 (fig. 1). 2 months later, recurrence of haemoptysis occurred, with DAH confirmed on BAL and CT scan, despite an ongoing corticosteroid therapy of $12.5 \mathrm{mg} \cdot \mathrm{day}^{-1}$ (fig. 1c). Intravenous immunoglobulins $2 \mathrm{~g} \cdot \mathrm{kg}^{-1}$ monthly were administered for 6 months. Both haemoptysis and radiological opacities disappeared and serological tests for ANCA became negative on immunofluorescence and ELISA. As shown in figure 1d, bronchiectasis disappeared on the chest CT scan. In July 2011, despite maintenance treatment with $7 \mathrm{mg} \cdot$ day $^{-1}$ of prednisone and $500 \mathrm{mg}$ of rituximab every 6 months, a first relapse occurred with haemoptysis recurrence, new radiological opacities on CT scan (fig. 1d) and intra-alveolar haemorrhage on BAL fluid analysis. ANCA testing was positive by fluorescence, but MPO-ANCA was not detected whereas BPI-ANCA was found by ELISA testing. Prednisone was increased to $80 \mathrm{mg} \cdot \mathrm{day}^{-1}$ and eight infusions of cyclophosphamide $\left(0.6 \mathrm{~g} \cdot \mathrm{m}^{-2}\right.$ at 3 -week intervals) were administered. A second remission was obtained, with simultaneous disappearance of cough, haemoptysis and radiological opacities. As depicted in figure 1d, bronchiectasis reversed on the CT scan concomitantly with BPI-ANCA disappearance.

This remission lasted for 16 months with a maintenance treatment including mycophenolate mofetil (1000 mg twice daily) and prednisone $10 \mathrm{mg} \cdot \mathrm{day}^{-1}$. A second relapse occurred, with coughing and haemoptysis with DAH. A thoracic CT scan showed the recurrence of bronchiectasis in the same location as previously. The ANCA titre rose to $1 / 640$ by immunofluorescence with BPI-ANCA (but not MPO) on ELISA testing. Cyclophosphamide ( $1 \mathrm{~g}$ in one pulse) combined with rituximab $(1 \mathrm{~g}$ on day 1 and on day 15) was started. A third remission was obtained, with complete disappearance of both bronchiectasis on thoracic CT scan and BPI-ANCA on ELISA assay, and is still ongoing after a follow-up period of 2 years with a maintenance treatment of rituximab at $500 \mathrm{mg}$ every 6 months and prednisone $5 \mathrm{mg} \cdot \mathrm{day}^{-1}$. The patient received cotrimoxazole $800 \mathrm{mg}$ three times per week to prevent opportunistic infections. No respiratory infectious complications occurred during follow-up. The nonseminomatous germ cell tumour remained in complete remission.

We report here the first case of a patient whose bronchiectasis was reversed while using solely an immunosuppressive regimen to treat alveolar haemorrhage associated with ANCA. This led us to reflect on the underlying pathophysiological mechanisms leading to bronchiectasis.

While some authors have reported vasculitis onset in patients with previously known chronic suppurative bronchiectasis, none had described bronchiectasis emerging and vanishing simultaneously with both ANCA-associated vasculitis onset and BPI-ANCA titre [5, 6]. BPI-ANCA positivity in chronic suppurative bronchiectasis, especially in cystic fibrosis, has been previously highlighted [7-9]. In cystic fibrosis, the presence of BPI-ANCA is associated with poorer respiratory functional evolution and linked to Pseudomonas aeruginosa presence in sputum $[7,10]$. Hence, BPI-ANCA production is usually thought to be the consequence of an intensive immune stimulation due to the chronic suppurative disease, but not as the cause of bronchiectasis. Conversely, our reported case seems to favour the role of an immune mechanism versus that of a pathogen-driven lesion in the establishment of bronchiectasis, since no pulmonary infection had been identified on BAL and no anti-infectious treatment had been given together with the immunosuppressive therapy. The immunosuppressive regimen, which mainly targeted ANCA production, allowed BPI-ANCA disappearance three times, always associated with bronchiectasis disappearance. Similarly, the reappearance of BPI-ANCA was each time, three times in a row, followed by that of the bronchiectasis.

A relationship between the ANCA-associated vasculitis and the testicular cancer of our patient could be evoked. ANCA-associated vasculitis onset is known to be a possible paraneoplastic manifestation and germ cell tumours have already been associated with vasculitis [11]. Moreover, symptoms can precede the diagnosis of the germ cell tumour then progress irrespective of the neoplastic disease [11-14]. However, most cancer-associated vasculitis is articular and cutaneous. 

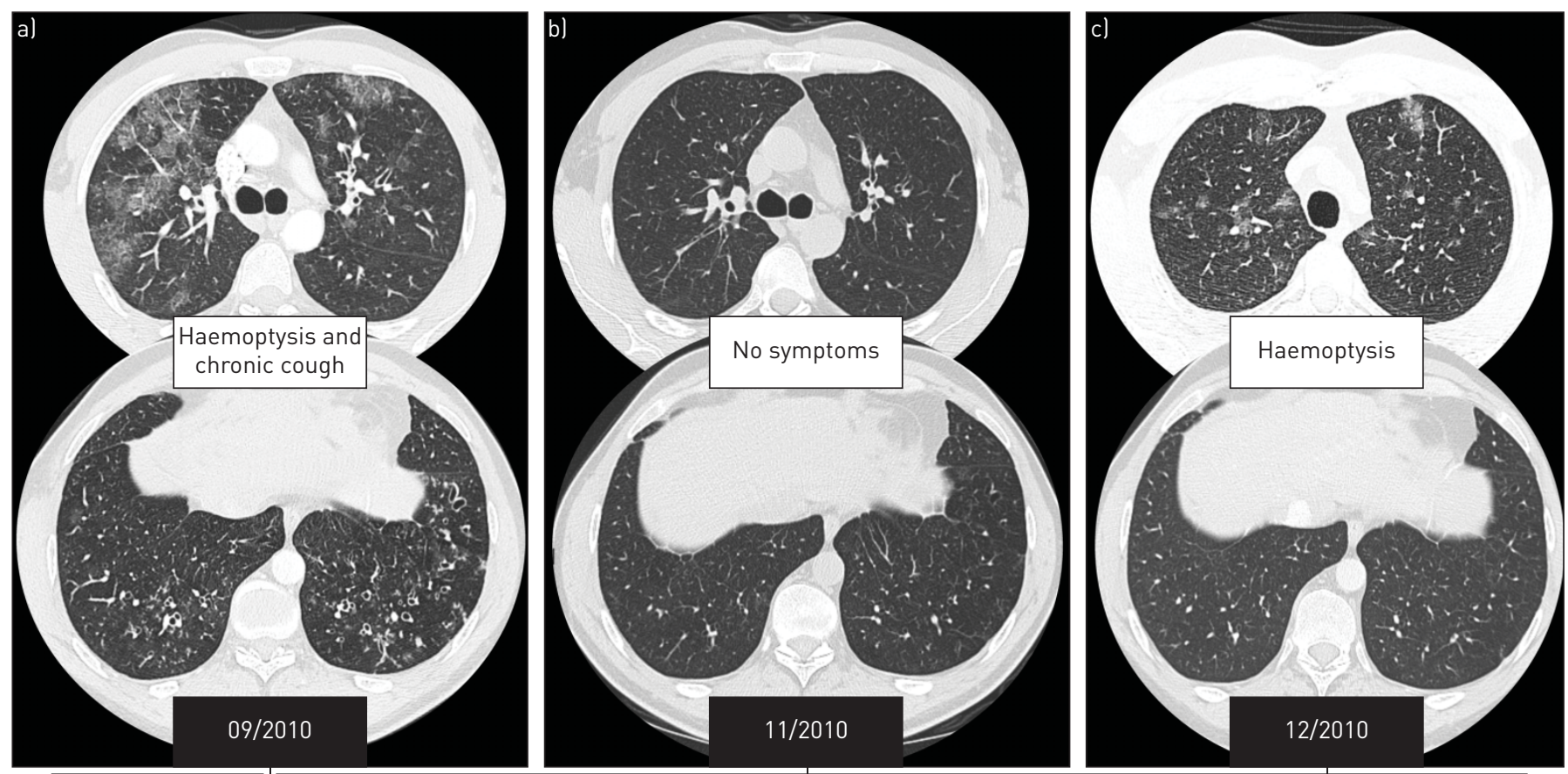

\begin{tabular}{|r|l|l|}
\hline Prednisone & $1 \mathrm{mg} \cdot \mathrm{kg}^{-1}(80 \mathrm{mg})$ taper \\
\hline Rituximab & $375 \mathrm{mg}^{-\mathrm{m}^{-2} \cdot \text { Week}^{-1} \times 4}$ \\
\hline i.V. Ig &
\end{tabular}

$20 \mathrm{mg}$

$15 \mathrm{mg}$

d)
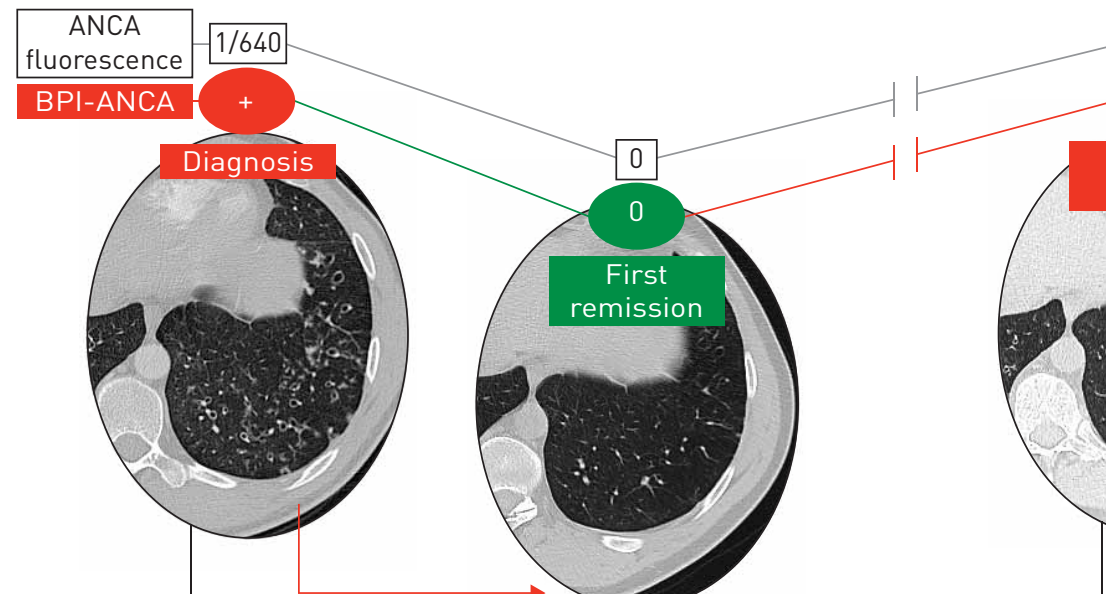

$1 / 640$
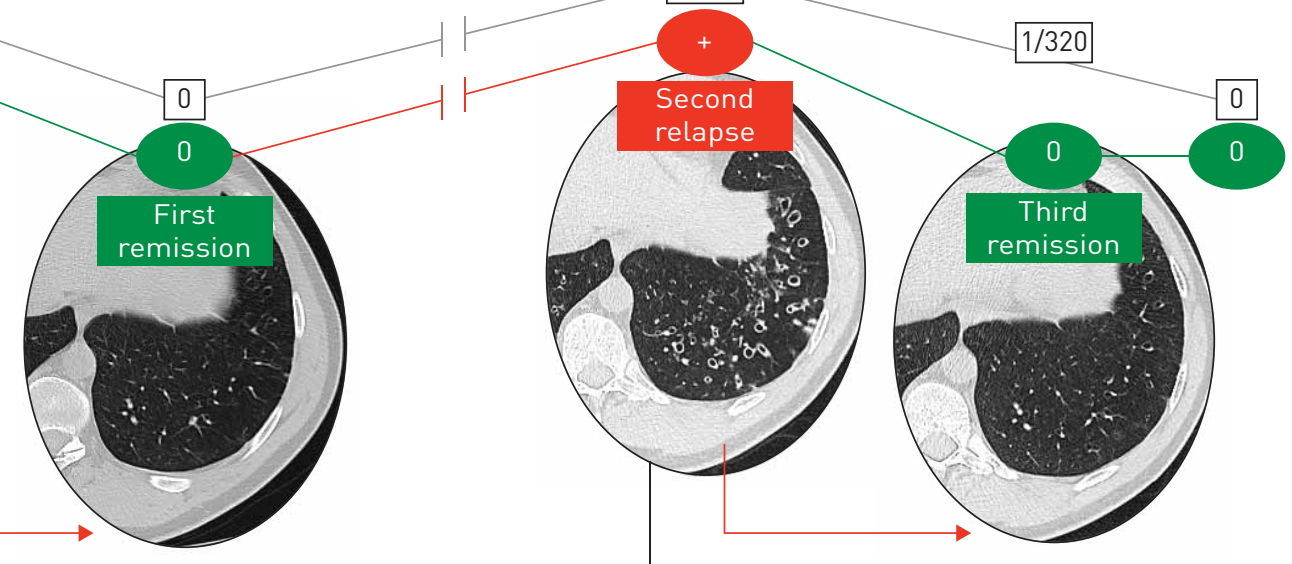

09/2010

$02 / 2011$

$07 / 2011$

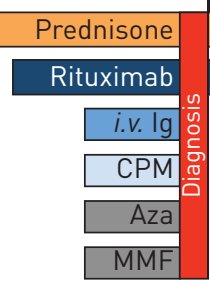

$80 \mathrm{mg}\left(1 \mathrm{mg} \cdot \mathrm{kg}^{-1}\right.$ tapered slowly)

\section{(1)}

$7 \mathrm{mg} \quad 80 \mathrm{mg}$
$12 / 2012$

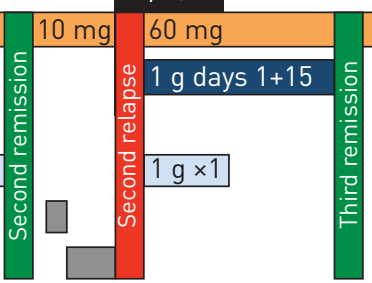

$10 / 2013$

FIGURE 1 Effectiveness of oral corticosteroids and rituximab on bronchiectasis disappearance. a) The computed tomography (CT) scan before antineutrophil cytoplasmic antibody (ANCA)-associated vasculitis treatment showed bilateral apical ground-glass opacities (apical image; top) with bi-basal bronchiectasis (basal image; bottom). b) Bronchiectasis rapidly disappeared after administration of corticosteroid therapy associated with rituximab, as demonstrated on the basal (bottom) image of the second CT scan performed 2 months later. c) After 3 months, the patient exhibited haemoptysis and alveolar haemorrhage on the apical image (top), without resurgence of bronchiectasis on the basal image (bottom) or bactericidal/permeability-increasing protein (BPI)-ANCAs, when corticosteroids were stepped down to $15 \mathrm{mg} \cdot \mathrm{day}^{-1}$. Intravenous immunoglobulins were administered, allowing first remission. d) Summary of the therapeutic course and the multiple relapses, focusing on the first and third remissions and highlighting the resurgence of bronchiectasis following BPI-ANCA testing positive. The bronchial wall thickness disappeared in all places, whereas the enlargement of the bronchi often disappeared, but persisted in a few areas. CPM: cyclophosphamide; Aza: azathioprine; MMF: mycophenolate mofetil. 
In conclusion, this report suggests that an autoimmune mechanism may be involved in the establishment of bronchiectasis and that BPI-ANCA could be an actor in bronchiectasis development rather than a marker of chronic infection. Moreover, this case outlines that bronchiectasis, which is usually considered as a sequel, could be a dynamic process with potential reversibility [2]. To date, guidelines suggest performing ANCA testing in bronchiectasis evaluation only if clinically relevant (i.e. looking for associated vasculitis), mainly because no therapeutic modification is expected in other cases $[1,15]$. We think that this report should lead to further evaluation of the practice of looking for ANCA in immunofluorescence and BPI-ANCA on ELISA test in patients with non-cystic diffuse bronchiectasis. Indeed, it could help to identify patients in whom administration of immunosuppressive regimens could help to avoid definitive bronchial damage, as in other bronchial diseases with immune hyperresponsiveness, such as allergic bronchopulmonary aspergillosis. immunosuppressive regimens? http://ow.ly/L7Nat

Raphael Lhote ${ }^{1}$, Christine Theodore ${ }^{2}$, Tasnime Issoufaly ${ }^{1}$, Dominique Francois ${ }^{3}$, Jean-Emmanuel Kahn ${ }^{4}$, Loïc Guillevin $^{5}$, Elisabeth Rivaud ${ }^{1}$, Camille Bron ${ }^{1}$, Marc Vasse ${ }^{3}$, Louis-Jean Couderc ${ }^{1,6,7}$ and Colas Tcherakian ${ }^{1,6,7}$

${ }^{1}$ Service de Pneumologie, Hôpital Foch, Suresnes, France. ${ }^{2}$ Service d'Oncologie, Hôpital Foch, Suresnes, France. ${ }^{3}$ Service de Biologie Clinique, Hôpital Foch, Suresnes, France. ${ }^{4}$ Service de Médecine Interne, Hôpital Foch, Suresnes, France.

${ }^{5}$ Service de Médecine Interne, Centre de Références Maladies Systémiques et Autoimmunes Rares, Hôpital Cochin, Assistance Publique-Hôpitaux de Paris, Université Paris Descartes, Paris, France. ${ }^{6}$ Faculté de Médecine, UFR des Sciences de la Santé Simone Veil, Université de Versailles Saint-Quentin-en-Yvelines, Montigny-Le-Bretonneux, France.

${ }^{7}$ UPRES EA220, Hôpital Foch, Université de Versailles Saint-Quentin-en-Yvelines, Suresnes, France.

Correspondence: Colas Tcherakian, Service de Pneumologie, Hôpital Foch, 40 rue Worth, 92150 Suresnes, France.

E-mail: c.tcherakian@hopital-foch.org

Received: Feb 242015 | Accepted after revision: March 182015 | First published online: May 142015

Conflict of interest: Disclosures can be found alongside the online version of this article at erj.ersjournals.com

\section{References}

1 Pasteur MC, Helliwell SM, Houghton SJ, et al. An investigation into causative factors in patients with bronchiectasis. Am J Respir Crit Care Med 2000; 162: 1277-1284.

2 Barker AF. Bronchiectasis. N Engl J Med 2002; 346: 1383-1393.

3 Fuschillo S, De Felice A, Balzano G. Mucosal inflammation in idiopathic bronchiectasis: cellular and molecular mechanisms. Eur Respir J 2008; 31: 396-406.

4 Cole PJ. Inflammation: a two-edged sword - the model of bronchiectasis. Eur J Respir Dis Suppl 1986; 147: 6-15.

5 Koninck JC, Diot E, Hazouard E, et al. Bronchectasies et polyangeite microscopique [Bronchiectasis and microscopic polyangiitis]. Rev Pneumol Clin 2002; 58: 290-295.

6 Kadowaki T, Yano S, Yamadori I, et al. A case of sinobronchial syndrome complicated with myeloperoxidase antineutrophil cytoplasmic antibody associated vasculitis: review of the literature. Intern Med 2012; 51: 763-767.

7 Lachenal F, Nkana K, Nove-Josserand R, et al. Prevalence and clinical significance of auto-antibodies in adults with cystic fibrosis. Eur Respir J 2009; 34: 1079-1085.

8 Carlsson M, Eriksson L, Pressler T, et al. Autoantibody response to BPI predict disease severity and outcome in cystic fibrosis. J Cyst Fibros 2007; 6: 228-233.

9 Wada Y, Kuroda T, Murasawa A, et al. Anti-neutrophil cytoplasmic autoantibodies against bactericidal/ permeability-increasing protein in patients with rheumatoid arthritis and their correlation with bronchial involvement. Mod Rheumatol 2010; 20: 252-256.

10 Mahadeva R, Dunn AC, Westerbeek RC, et al. Anti-neutrophil cytoplasmic antibodies (ANCA) against bactericidal/permeability-increasing protein (BPI) and cystic fibrosis lung disease. Clin Exp Immunol 1999; 117: 561-567.

11 Fain O, Hamidou M, Cacoub P, et al. Vasculitides associated with malignancies: analysis of sixty patients. Arthritis Rheum 2007; 57: 1473-1480.

12 Tan E, Young D, McLaren B, et al. Early-stage testicular cancer: a rare association with dermatomyositis. Australas J Dermatol 2010; 51: 139-141.

13 Prüss H, Voltz R, Flath B, et al. Anti-Ta-associated paraneoplastic encephalitis with occult testicular intratubular germ-cell neoplasia. J Neurol Neurosurg Psychiatry 2007; 78: 651-652.

14 Sprossmann A, Müller RP. Urtikaria-Vaskulitis-Syndrom beim metastasierenden malignen Hodenteratom [Urticaria-vasculitis syndrome in metastatic malignant testicular teratoma]. Hautarzt 1994; 45: 871-874.

15 Pasteur MC, Bilton D, Hill AT, et al. British Thoracic Society guideline for non-CF bronchiectasis. Thorax 2010; 65: 577. 